\title{
About Organic Systems Origin According to Equilibrium Thermodynamic Modeles of Molecules Distribution in Interstellar Medium
}

\author{
Michel Yu. Dolomatov ${ }^{1,2}$, Nadezhda A. Zhuravleva ${ }^{2} \&$ Diana R. Tanatarova $^{2}$ \\ ${ }^{1}$ Physical electronics and nanophysics department, Bashkir State University, 32 Zaki Validi St., Ufa, Russian \\ Federation \\ ${ }^{2}$ Research laboratory «Physics of Electronic Processes and Nanophysics», Department of Physics, Ufa State \\ Academy of Economics and Service, 145 Chernyshevskiy St., Ufa, Russian Federation \\ ${ }^{3}$ Economic Informatics Department, Ufa State Aviation Technical University, Karla Marksa Street, 12, Ufa \\ 450000, Russian Federation
}

Correspondence: Nadezhda A. Zhuravleva, Ufa State Aviation Technical University, Karla Marksa Street, 12, Ufa 450000, Russian Federation. Tel: 7-919-158-7048. E-mail: zhuravliova80@mail.ru, dolomatov@gmail.com

Received: July 20, 2014 Accepted: August 4, 2014 Online Published: August 27, 2014

doi:10.5539/apr.v6n5p65 URL: http://dx.doi.org/10.5539/apr.v6n5p65

\begin{abstract}
Problem of an natural organic systems origin - amino acids, nucleotides and other construction elements of life and also natural hydrocarbonic systems to which oil and gas belong is actual not only with fundamental, but also from the practical point of view. We know that hydrocarbonic resources of a planet are steadily exhausted. At present there are not methods and models to calculate the resources of oil and life-related molecules in interstellar environment. In this paper is developed the mathematical model of the molecules composition distribution in the interstellar environment on thermodynamic potentials using methods of the probability theory, the mathematical and physical statistics and the equilibrium thermodynamics. Based on this model are estimated the resources of life-related molecules, amino acids and the nitrogenous bases in the interstellar medium. The possibility of the oil hydrocarbons molecules formation is shown. The given calculations confirm Sokolov's and Hoyl's hypotheses about the possibility of the oil hydrocarbons formation in Space. Results are confirmed by data of astrophysical supervision and space researches.
\end{abstract}

Keywords: origin of natural organic systems, molecules resources in the interstellar medium, life-related molecules, hydrocarbonic systems (oil, gas), mathematical model

\section{Introduction}

Problem of an natural organic systems origin - amino acids, nucleotides and other construction elements of life and also natural hydrocarbonic systems to which oil and gas belong it is actual not only with fundamental, but also from the practical point of view. We know, that hydrocarbonic resources of a planet are steadily exhausted.

Along with hypotheses of a spontaneous origin of life, and organic substance also panspermia hypotheses are known which explains a high speed of evolution with introduction on our planet of organic chemistry from space, including construction elements of a live matter - biologically active agents (Horowitz, 1986), amino acids, nitrogenous bases, molecules of nucleinic acids. So outstanding English astrophysicist, F.Hoyl and the S. Wikramasing in 1981 assumed existence of the vital molecules, viruses and dispute of microorganisms in interstellar space in space dust clouds (Wickramasinghe, 2003). By their estimates, in the atmosphere of Earth the 1018th dispute annually (Voytkevich, 1988) arrives.

Direct proof of possibility of space oil and life origin is detection of organic molecules in substance of meteorites, comets and the interstellar environment (Anders, Hayatsu, \& Studier, 1973; Interstellar molecules, 2011; Pascale \& Steven, 2000). Research of space organic substance began nearly two centuries ago (Voytkevich, 1988), so in 1834 great chemist Y. Bertselius allocated for the first time organic substance from a meteorite of Ala-is which carry to a class carbonaceous chondrite. In 1838 one of founders of organic chemistry F. Vyoler allocated from carbonaceous chondrite bituminous oily substance. In 1864 french chemist O. Klets proved that black, insoluble in 
water oily substance of Orgeyl meteorite represents itself a mix of organic compounds similar to organic chemistry of oil, peat, brown coal. According to Klets organic substances in meteorites, mean existence of organized organic matter in heavenly bodies. In 1889 Y. Simashko found organic substances of bituminous type in Migei meteorite.

Basing on researches of chemists, in 1889 Russian geologist V. Sokolov in report at meeting of the Moscow society of scientists offered the space theory of an origin of oil (Kudryavtsev, 1973). According to Sokolov, hydrocarbons existed in primitive substance of Earth. In process of planet cooling at its creation from gas-and-dust clouds oil was absorbed and dissolved in the liquid melted magma. In further geological history at Earth crust from magma hydrocarbons escaped. These hydrocarbons rose on fold faults in the top layers of lithosphere with formation of oil collectors. This hypothesis isn't contradicted by ideas which have been put forward in 1954 by N. Kudryavtsev (Kudryavtsev, 1973). N. Kudryavtsev offered a hypothesis of formation of hydrocarbons in deep hot zones of Earth from hydrocarbons pyrolysis products, which containing alkyl hydrocarbons radicals like $\mathrm{CH}, \mathrm{CH}$, $\mathrm{CH} 3$. These particles serve as a material for oil formation in colder top layers and are escaped into planet mantel rock through faults. To similar ideas investigating emission of hydrocarbons from a surface of Earth and planets Thomas Gold (Thomas Gold, 1988) came. Some other way to a conclusion about a space origin of oil came known scientist A.S.Eygenson who developed the space theory (Eygenson, 1990; Eygenson, 1991; Eygenson, Sheih-Ali, 1986). In these works for justification of an abiogenous hypothesis it applied general to all natural and technogenic hydrocarbonic systems universal regularity of normal (Gaussian) distribution of the component and fractional structure (CFS) on the standard temperatures of boiling (STB). Eygenson studied regularities of this distribution for the majority of oil fields of our planet. The genetic relationship absolutely different oils from the point of view of the abiogenous theory was revealed.

According to Grinberg (Grinberg, 1984), particles of a space dust have a difficult structure. They consist of kernel with mainly silicate structure surrounded with a cover from ice, including organic substances. In a cover, are possible catalytic processes of destruction and the condensation, structures conducting to complication and increase in molecular weight of molecules. The most part of these microscopic dust particles - planetesimales are formed from silicate nanoparticles of strong substance which has arisen in the atmosphere of a cold giant star or at explosion and cooling of protostar substance.

At destruction of the motes including organic substances under the influence of exposure from a surface of silicate particles compounds, which form giant molecular clouds (GMC), are formed. According to radio astronomy, GMC occupy considerable areas of space (from 1 to 400 Parsec), have the weight equal from 1 up to 70 mass of the Sun. In these clouds stars and planets are actively formed. Composition of GMC includes organic and inorganic compounds, including hydrocarbons of a number of methane, nitrogen-heteroatomic and an oxy compound, for example, glycine, cyanogen, cyanoacetylene, amines (Lyubarsky \& Syunyaev, 1991; Rudnitsky, ND). Now according to radio and infrared astronomy over 140 molecules and molecular particles (Lovas, 1986; Lovas, 1992; The Cologne Database, ND) are known.

Currently researchers carry out search of various mathematical and physico-chemical models of organic substance formation.

Since the well-known experiences in 1952 - 1955 of Ury and S. Miller (Miller, 1953) in laboratory from elementary substances - a hydrogen-ammonia-metane mix at a transmission through it electric discharges difficult organic molecules, including the elementary amino acids were received.

Lack of these and later experiences was, that in laboratory it is impossible to reproduce all complex of space influences. Therefore the special attention is paid in recent years to computer experiments.

Thus on computer stages of thermodynamic, cosmochemical and dynamic evolution of a doplanetny gas-and-dust disk from planetesimales - the smallest germs of planets are considered. By means of computing methods imitating modeling of creation and evolution of a subdisk, dust condensations and primary planetesimales (Makalkin \& Ziglina, 2012; Makalkin et al., 1998) is carried out, processes of evolution of a solar protoplanetary cloud (Kolesnichenko \& Marov, 2006) are investigated. Complex problems are solved, as a rule, by numerical methods of chemical kinetics at micro and macroscopic scales with application of Monte-Carlo method algorithms (Marov \& Kolesnichenko, 2012; Tsvetkov \& Shematovich, 2009, 2010).

Problem of computer researches is creation of numerical models of chemical kinetics of formation of organic molecules in interstellar chemically active gas-and-dust environments. These models include catalytic reactions on surfaces of gas-and-dust covers, and also a chemical exchange between dust and gas system. Essential difficulties on a way of such researches is absence of knowledge of behavior of substance in extreme conditions of space. Laws of the chemical kinetics, known it is in vitro difficult to transfer to space scales and environment with enormous gravitational, radiation and electromagnetic influence. Therefore thermodynamic researches which 
don't demand studying of elementary stages molecules formation process are actual. In particular, a problem of this research is development of phenomenological thermodynamic model of organic substances existence probability proceeding from astrophysical data.

\section{Research Methods}

In this paper interstellar medium is considered as equilibrium thermodynamic system. The basis of this hypothesis is the comparison of the relaxation time of an observer and the relaxation time of various molecules in interstellar cosmic medium. As it follows from the radio-spectroscopy data, lifetime for most of cosmic molecules is significant. For example, molecules of ammonia, methane and benzene have been existing on the distance of a few thousands and a few millions of light years. It is much more than the time of human observation. Therefore, we can suggest, that the molecule system in cold areas $(\mathrm{T}=2-700 \mathrm{~K})$ of interstellar giant molecular clouds GMCs may be in thermodynamic equilibrium state. The existence of more than 165 molecules in the GMCs (The Cologne Database), confirm this fact. At higher temperatures under the influence of hard radiation, simple organic molecules dissociate with ions or free radicals formation. Thus, from the fact of sustainable observation of stable molecules in the interstellar medium, it follows that the principle of local equilibrium in some areas of the interstellar medium takes place, and if so, then the laws of equilibrium thermodynamics can be used for quantitative assessment of molecular resources. In the basis of the most of physical-chemical calculations in the interstellar medium, the conditions of local equilibrium are taken into account (Maloney, 1986; Lee, Snell, \& Dickman, 1996; Sakamoto, 1999; Bains et al., 2006; Vasyunin, 2008).

In hot areas in which temperature exceeds $\mathrm{T}=104-105 \mathrm{~K}$ in the conditions of external influences there are processes for which local thermodynamic equilibrium during a short interval of time is broken. It is possible in hot areas in which processes of condensation of a matter develop, but in comparison with the volume of cold areas hot areas occupy very small volume of a space therefore in whole the principle of local thermodynamic equilibrium in space is carried out. If the volume of visible part of the Universe reaches $1084 \mathrm{~m} 3$, the average volume of hot areas of stars makes $1025 \mathrm{~m}^{3}$, the total amount of hot areas makes:

$$
V=10^{25} \cdot 10^{27}=10^{52} \mathrm{M} 3 .
$$

Then the probability of ingress of molecules into hot areas, where there is a violation of local thermodynamic equilibrium, makes:

$$
P=\frac{V_{\text {hot }}}{V_{\text {Universe }}}=\frac{10^{52}}{10^{84}}=10^{-32}
$$

that also confirms existence of local thermodynamic equilibrium in Space.

Also, it is known that the gas density in interstellar medium is very low. But in the same time it is known that molecular particles of organic compounds are formed not in volume of vacuum with a small density, but in areas, where probability of collision of particles is large, for example, on surface of gas-and-dust particles which make considerable part (to $5 \%$ of mass. ) from substance of interstellar molecular gas clouds.

The first equilibrium thermodynamic models of molecular systems distribution in interstellar medium was considered in the research (Dolomatov, 2005). Let us examine thermodynamic features of GMCs as multi-component systems with the chemical composition chaos (MSCC). According to the theory (Dolomatov, 2005), the GMCs belong to the MSCC.

In works (Dolomatov, 2004, 2005; Dolomatov \& Kostyleva, 2002) taking into account thermodynamics of multicomponent systems with chaos of a chemical composition (MSCC) (Dolomatov, 1990, 2000) and data of astrophysics possibility of oil and biochemical systems formation at a formation stage in GMC and an akrektion of a gas-and-dust cloud is shown. Calculations of organic substances and hydrocarbons resources were carried out with use of function of composition on heat of formation distribution. On the basis of these estimates the structure of primary hydrocarbonic mix, so-called protooil was defined. Further these ideas developed in works (Dolomatov \& Zhuravleva, 2012a, 2012b, 2012c, 2012d, 2014). In these researches authors don't set as the purpose to describe detailed mechanisms an origin of hydrocarbons, and also information molecules of RNA and DNA which are unknown. The main researches task was creation of mathematical model of organic compounds resources of with use of composition on Helmholtz's free energy distribution functions.

At present is unknown the full range of physical and chemical processes in the GMCs, determined by the temperature and concentration gradients, the shock waves in the conditions of giant electromagnetic and gravitational fields, etc. That is why, it is incorrect to use strictly-defined known in laboratory conditions mechanisms of chemical reactions. Therefore, a phenomenological approach is preferred for the chemical 
composition distribution in GMCs models in which only the final steady condition of multicomponent molecular system is considered (Dolomatov, 2005; Dolomatov \& Zhuravleva, 2013).

Following the theory (Dolomatov, 2005), we assign the existence of a statistical ensemble from a large number of components in an isolated MSCC $-\mathrm{N}$, each of them is characterized by a specific value of the thermodynamic potential and properties. Let us define the probability of the existence of $\mathrm{M}$ components with specific thermodynamic potential or properties in such a system, which is different from the average system property. Such a probability (W) is determined by the binomial (Bernoulli) distribution:

$$
W=C_{N}^{M} \cdot p^{M} \cdot(1-p)^{N-M},
$$

where CNM- binomial coefficient: $N$ by $M ; p=1-1 / z$ the probability of the chemical difference $z$ micro conditions components in an isolated system; when $\mathrm{z}=>\infty$, the system is constructed from entirely different components, $\mathrm{p}$ $\Rightarrow 1$. When $\mathrm{z}=1 \mathrm{p}=0$, the system consists of a single component, but such a situation is not possible, according to the second law of thermodynamics, the system conditions diversity increase takes place. When $p \rightarrow 0$, we obtain the system of Poisson nature of thermodynamic characteristics distribution (pure substances).

In typical MSCC cases, the possibilities $0<\mathrm{p}<1$ are realized (for example, hydrocarbon systems). This can be concluded from the Laplace-Moivre theorem that in this case (2) Gaussian distribution of the composition by thermodynamic potentials and properties of the components is formed.

The MSCC thermodynamics indicates that the normal law of composition distribution by free energies should be observed:

$$
F\left(p_{i}\right)=\frac{1}{\sigma \sqrt{2 \pi}} \exp \left[-\left(\frac{\Delta F-\Delta \bar{F}}{\sigma \sqrt{2}}\right)^{2}\right],
$$

where $p_{i}$ - probability of existing molecules in MSCC with the defined free energy (Helmholtz energy), $\sigma^{2}-$ dispersion, $\Delta F$ - free energy (Helmholtz energy) of i-compound, $\Delta \bar{F}$ - average value of all molecular compounds.

Free energy (Helmholtz energy) of the compounds are calculated with the help of statistical physics and spectroscopy data.

The defect in the previous study was due to the lack of strict statistical approach which takes into account micro statistics and inaccuracy of calculation algorithms, which consider several distribution laws. This fact finally led to the ambiguity in the statistical estimates.

The purpose of this study is to estimate the molecules resources in the GMCs in accordance with the normal distribution law.

\section{Subjects of Research}

The objects of the research are molecules, the existence of which in GMCs was proved by using radio spectral methods (Lovas, 1986; Lovas, 1992; The Cologne Database, ND). The information on 67 molecular organic compounds has been analyzed: the oxygen-containing molecules, nitrogen-containing molecules, the methane series and the acetylene hydrocarbons. In addition, taking into account the recent data, the aromatic hydrocarbons, fullerenes, glycine and simple carbohydrates have also been investigated (Cami et al., 2010). The organic compounds standard enthalpy of formation at the temperature of $298 \mathrm{~K}$ has been selected. In order to study the free energy, the temperature range from $2 \mathrm{~K}$ to $600 \mathrm{~K}$ has been selected, i.e. the temperature range, which provides simple organic molecules stable existence in the GMCs substance in low density conditions. Free energy (Helmholtz energy) of the compounds are calculated with the help of molecular and spectroscopy data (Landau \& Lifshitz, 1996).

The basic assumptions of the mathematical model of the chemical composition in GMCs distribution:

1). Sizes of the metagalaxy part, where material resource evaluation is carried out, are limited by the visibility horizon of modern means of examination.

2). In accordance with the modern physics conceptions, the universal isotropy and homogeneity of space are assumed, as well as the GMCs formation processes permanence in different areas of space.

3). Despite the fact that in some areas of GMCs the star formation takes place and the substance is in the state of non-equilibrium plasma, there are areas in the system that are in the state of local thermodynamic equilibrium and have temperatures $<1000 \mathrm{~K}$, in which the molecules of organic substances are stable. 
4). The phenomenological model: GMCs represent a range of similar cybernetic «black boxes» within which the complex of physical and chemical conditions is analogous. They are exposed to perturbation environmental conditions. The specific chemical reaction mechanism is not considered. The input parameters are the properties, the output parameters are the amount of substance.

5). When constructing the phenomenological distribution models, the averaged in accordance with the large numbers effect law data concerning the areas of the GMCs with a uniform set of conditions are considered. According to Lyapunov's theorem, the regular composition distribution by the properties in case of homogeneous conditions complex should be expected but considering the conditions heterogeneity, which generate the multi-dimensional distributions and the condensation physical processes (the substance accretion).

6). The carbon content in the universe is constant, i.e. its flow rate in the process of accretion and star formation equals to the rate of its reproduction in the nuclear fusion process and supernova explosions. The explosions of supernovae are considered to enrich space with active particles of carbon.

7). This estimate does not include the hidden mass, which according to various assessments, 5 - 10 times exceeds the visible mass.

These assumptions are sufficient for the offered phenomenological approach in which only the final steady condition of multicomponent molecular system is considered (Dolomatov \& Zhuravleva, 2013). These assumptions are necessary in the conditions of limited information on processes which exist in the interstellar medium within sight of astronomical instruments of observations.

On the bases of the above stated, the following model is suggested:

$$
M_{i}=X F\left(p_{i}\right) Q N_{g} M_{0},
$$

where $p i-i$-molecule existence probability in the GMCs,

$F(p i)$ - the corresponding probability distribution function;

$Q$ - average number of GMC in the galaxy,

$\mathrm{Ng}$ - number of galaxies in the visible part of the universe,

$M o=2 \cdot 10^{30} \mathrm{~kg}-$ the Sun mass,

$x=1$ - the coefficient, which takes into account the organic molecules loss during the star formation processes and their reproduction during supernova stars explosions.

In accordance with the estimates, accepted in the astrophysics (Binney J, Merrifield M., 1998) $Q=1 \div 10^{6} ; \mathrm{Ng}=10^{10}$; $\mathrm{x}=1$.

\section{Results}

The calculations algorithm:

1) Calculation free energy (Helmholtz energy) of the compounds with the help of statistical physics and spectroscopy data (Table 1).

2) Construction of variational series and calculation of their characteristics on thermodynamic properties of compounds;

a. Ranking of the calculated values of properties of compounds of GMC:

$$
x_{\min }=h 1 ; h 2 ; h 3 ; \ldots h i=x_{\max } .
$$

b. Defining of separate intervals from the values of properties (Table 2).

Determination of size of an interval with equal intervals is made for creation of variational series as follows:

a) Calculation of the difference between maximum and minimum values of a sign of primary row (variation range, $\mathrm{R}$ ):

$$
R=x_{\max }-x_{\min }
$$

b) Calculation of intervals number, $k$, using the Sturges formula:

$$
k=1+3.322 \lg n,
$$

where $n$-total number of studied units in the aggregate. 
c) Calculation of an interval size:

$$
h=R / k \text {. }
$$

d) Determination of average value of property in an interval:

$$
\bar{x}=\frac{x_{i}+x_{i+1}}{2},
$$

for each interval.

e) Defining of relative frequencies (relative probabilities) of compounds existence:

$$
w i=n i / n,
$$

where $n_{i}$ - appearance frequency of value from this interval;

$n$ - total number of studied units in the aggregate.

f) Calculation of arithmetical mean of a variational series:

$$
\bar{X}_{B . p .}=\sum_{i=1}^{k} X_{i} W_{i},
$$

где $w_{i}=n_{i} / n$ - relative probabilities of values.

3) Construction of cumulative distribution curves of compounds and their analysis.

After graphic construction of cumulative distribution curves of relative probabilities on thermodynamic properties is carried out their analysis for establishment of the theoretical law of distribution of a random variable. For this purpose it is necessary to define a kind and parameters of the law of distribution.

As it is established above that in typical MSCC, in particular in GMC, are realized the possibilities $0<\mathrm{p}<1$, then from Moivre-Laplassa theorem follows that in this case is formed the Gaussian distribution of composition on thermodynamic potentials and properties of components.

Therefore we make a hypothesis of normal (Gaussian) distribution of composition on thermodynamic properties of components.

Further is calculated the main characteristics of the normal (Gaussian) law of distribution of composition using known to all in statistics formulas: arithmetical mean of a variational series, dispersion of a variation series, an average quadratic deviation, mode of distribution, coefficient of skewness, coefficient of skewness according to Pearson, kurtosis (Table 3).

Testing of a hypothesis about the normal law of distribution by means of well-known in statistics $\chi 2$-Pearson's criterion.

If the hypothesis about normal distribution of structure isn't disproved (in our case it isn't disproved), so probability distribution of formation of compounds in GMC is normal.

4) Calculation of molecules formation probabilities in GMC with a certain free energy is carry out, using the law of normal distribution on a formula (2) (Table 4);

5) Resources assessment of the corresponding compounds is carried out on a formula (3) (Table 5, 6).

On the base of this algorithm is developed information system of an assessment of molecules resources of in the interstellar medium (Certificate on the state registration, 2014).

\section{Discussion of Results}

Normal distribution of probability of existence of organic compounds with a certain free energy in GMC is confirmed with criteria $\chi 2$-Pearson and Kolmogorova-Smirnov. Probabilities of existence of organic molecules are calculated on normal distribution law of free energies. With growth of number of atoms in molecules the probability of their existence decreases, but isn't zero. 
Table 1. Free energy (Helmholtz energy) of formation at $100 \mathrm{~K}$ in GMC

\begin{tabular}{|c|c|c|}
\hline № & Compound & $\begin{array}{l}\text { free energy (Helmholtz energy), } \\
\qquad \mathrm{kJ} / \mathrm{mol}\end{array}$ \\
\hline 1 & $\mathrm{CO}$ & $-37,6$ \\
\hline 2 & $\mathrm{CS}$ & $-8,3$ \\
\hline 3 & $\cos$ & 10,5 \\
\hline 4 & $\mathrm{C}_{2} \mathrm{O}$ & 2,1 \\
\hline 5 & $\mathrm{CO}_{2}$ & 13,0 \\
\hline 6 & $\mathrm{C}_{2} \mathrm{~S}$ & $-1,9$ \\
\hline 7 & $\mathrm{C}_{2} \mathrm{H}_{2}$ & 59,5 \\
\hline 8 & $\mathrm{H}_{2} \mathrm{CO}$ & 52,8 \\
\hline 9 & $\mathrm{H}_{2} \mathrm{CS}$ & 46,3 \\
\hline 10 & $\mathrm{HNCO}$ & 37,3 \\
\hline 11 & $\mathrm{HOCN}$ & 41,4 \\
\hline 12 & $\mathrm{HSCN}$ & 20,9 \\
\hline 13 & $\mathrm{c}-\mathrm{SiC}_{3}$ & 14,3 \\
\hline 14 & $\mathrm{CH}_{4}$ & 105,3 \\
\hline 15 & $\mathrm{CH}_{2} \mathrm{CO}$ & 66,2 \\
\hline 16 & $\mathrm{CH}_{2} \mathrm{NH}$ & 85,6 \\
\hline 17 & $1-\mathrm{C}_{3} \mathrm{H}_{2}$ & 66,2 \\
\hline 18 & c- $\mathrm{C}_{3} \mathrm{H}_{2}$ & 60,8 \\
\hline 19 & $\mathrm{HCCCN}$ & 59,0 \\
\hline 20 & $\mathrm{HC}_{2} \mathrm{NC}$ & 43,5 \\
\hline 21 & $\mathrm{HC}(\mathrm{O}) \mathrm{CN}$ & 52,3 \\
\hline 22 & $\mathrm{HCOOH}$ & 68,2 \\
\hline 23 & $\mathrm{NH}_{2} \mathrm{CN}$ & 73,3 \\
\hline 24 & $\mathrm{SiH}_{4}$ & 55,8 \\
\hline 25 & $\mathrm{CH}_{3} \mathrm{OH}$ & 116,0 \\
\hline 26 & $\mathrm{CH}_{3} \mathrm{CN}$ & 100,5 \\
\hline 27 & $\mathrm{CH}_{3} \mathrm{NC}$ & 97,1 \\
\hline 28 & $\mathrm{H}_{2} \mathrm{CCNH}$ & 97,6 \\
\hline 29 & $\mathrm{NH}_{2} \mathrm{CHO}$ & 94,6 \\
\hline 30 & НСCCHO & 81,6 \\
\hline 31 & $\mathrm{c}-\mathrm{H}_{2} \mathrm{C}_{3} \mathrm{O}$ & 86,2 \\
\hline 32 & $\mathrm{CH}_{3} \mathrm{SH}$ & 96,0 \\
\hline 33 & $\mathrm{CH}_{2} \mathrm{CHCN}$ & 113,5 \\
\hline 34 & $\mathrm{CH}_{3} \mathrm{NH}_{2}$ & 148,2 \\
\hline 35 & $\mathrm{HC}_{5} \mathrm{~N}$ & 87,1 \\
\hline 36 & $\mathrm{CH}_{3} \mathrm{CHO}$ & 126,4 \\
\hline 37 & $\mathrm{H}_{2} \mathrm{CCHOH}$ & 129,4 \\
\hline 38 & $\mathrm{c}-\mathrm{C}_{2} \mathrm{H}_{4} \mathrm{O}$ & 128,1 \\
\hline 39 & $\mathrm{CH}_{3} \mathrm{CCH}$ & 129,9 \\
\hline 40 & $\mathrm{CH}_{3} \mathrm{CCCN}$ & 128,5 \\
\hline 41 & $\mathrm{HCOOCH}_{3}$ & 136,1 \\
\hline 42 & $\mathrm{CH}_{3} \mathrm{COOH}$ & 141,9 \\
\hline 43 & $\mathrm{H}_{2} \mathrm{C}_{6}$ & 106,8 \\
\hline 44 & $\mathrm{CH}_{2} \mathrm{OHCOH}$ & 136,5 \\
\hline 45 & $1-\mathrm{HC}_{6} \mathrm{H}$ & 115,6 \\
\hline
\end{tabular}




\begin{tabular}{lcl}
\hline 47 & $\mathrm{CH}_{2} \mathrm{CHCHO}_{4}$ & 139,4 \\
47 & $\mathrm{CH}_{2} \mathrm{CCHCN}$ & 124,3 \\
48 & $\mathrm{H}_{2} \mathrm{NCH}_{2} \mathrm{CN}$ & 144,0 \\
49 & $\mathrm{CH}_{3} \mathrm{CH}_{2} \mathrm{OH}$ & 187,1 \\
50 & $\mathrm{CH}_{3} \mathrm{C}_{4} \mathrm{H}$ & 157,8 \\
51 & $\mathrm{CH}_{3} \mathrm{CH}_{2} \mathrm{CN}$ & 173,3 \\
52 & $\mathrm{HC}_{7} \mathrm{~N}$ & 114,7 \\
53 & $\mathrm{CH}_{3} \mathrm{OCH}$ & 185,1 \\
54 & $\left.\mathrm{CH}_{3} \mathrm{C}_{3} \mathrm{O}\right) \mathrm{NH}_{2}$ & 168,7 \\
55 & $\mathrm{C}_{3} \mathrm{H}_{6}$ & 187,1 \\
56 & $\left(\mathrm{CH}_{3}\right)_{2} \mathrm{CO}$ & 200,1 \\
57 & $\mathrm{CH}_{3} \mathrm{C} 5 \mathrm{~N}$ & 157,0 \\
58 & $\left(\mathrm{CH}_{2} \mathrm{OH}\right)_{2}$ & 196,8 \\
59 & $\mathrm{CH}_{3} \mathrm{CH}_{2} \mathrm{CHO}$ & 198,9 \\
60 & $\mathrm{NH}_{2} \mathrm{CH}_{2} \mathrm{COOH}$ & 185,5 \\
61 & $\mathrm{CH}_{3} \mathrm{C}_{6} \mathrm{H}$ & 185,9 \\
62 & $\mathrm{C}_{2} \mathrm{H}_{5} \mathrm{OCHO}$ & 208,1 \\
63 & $\mathrm{HC}_{9} \mathrm{~N}$ & 142,8 \\
64 & $\mathrm{C}_{2} \mathrm{H}_{5} \mathrm{OCH}$ & 257,1 \\
65 & $n-\mathrm{C}_{3} \mathrm{H}_{7} \mathrm{CN}$ & 245,8 \\
66 & $\mathrm{C}_{6} \mathrm{H}_{6}$ & 239,1 \\
67 & $\mathrm{HC}_{11} \mathrm{~N}$ & 170,8 \\
\hline & &
\end{tabular}

Table 2. The variational series calculated on free energy (Helmholtz energy) of formation at $100 \mathrm{~K}$ in GMC Distribution

\begin{tabular}{cccccc}
\hline $\begin{array}{c}\text { Variation interval of } \\
\text { free energy }\end{array}$ & $\begin{array}{c}\text { Number of } \\
\text { compounds in an } \\
\text { interval, } \mathrm{n}\end{array}$ & $\begin{array}{c}\text { Mean free } \\
\text { energy in an } \\
\text { interval, } \\
\mathrm{kJ} / \mathrm{mol}\end{array}$ & $\begin{array}{c}\text { Existence of } \\
\text { compounds probability } \\
\text { (empirical), }\end{array}$ & $\begin{array}{c}\text { Calculated probability } \\
\text { of compounds } \\
\text { existence }\end{array}$ \\
\hline$-37,64$ & 4,07 & 4 & $-16,79$ & 0,065 & 0,065 \\
4,07 & 45,77 & 7 & 24,92 & 0,108 & 0,108 \\
45,77 & 87,48 & 15 & 66,63 & 0,150 & 0,150 \\
87,48 & 129,19 & 15 & 108,33 & 0,177 & 0,177 \\
129,19 & 170,89 & 13 & 150,04 & 0,177 & 0,177 \\
170,89 & 212,60 & 10 & 191,75 & 0,150 & 0,150 \\
212,60 & 254,31 & 2 & 233,45 & 0,108 & 0,108 \\
254,31 & 296,01 & 1 & 275,16 & 0,065 & 0,065 \\
\multicolumn{2}{c}{ Total } & 67 & & 1,000 & 1,000 \\
\hline
\end{tabular}

Table 3. Distribution criteria at $100 \mathrm{~K}$

\begin{tabular}{ccccccc}
\hline \multirow{2}{*}{ Distribution } & \multicolumn{5}{c}{ Index } \\
\cline { 2 - 7 } & $\begin{array}{c}\text { Pearson } \chi^{2} \\
\text { (table estimated) }\end{array}$ & $\begin{array}{c}\text { Mean, } \\
\mathrm{kJ} / \mathrm{mol}\end{array}$ & Variance & $\begin{array}{c}\text { Mode, } \\
\mathrm{KJ} / \mathrm{mol}\end{array}$ & Skewness & Kurtosis \\
\hline $\begin{array}{c}0,231 \\
\text { free energy (Helmholtz } \\
\text { energy) of formation } \\
\begin{array}{c}\text { standard enthalpy of } \\
\text { formation }\end{array}\end{array}$ & $\begin{array}{c}\left.\chi^{2} \text { table }=101,88\right) \\
0,197 \\
\left(\chi^{2} \text { table }=101,88\right)\end{array}$ & 142,0 & $(92,0)^{2}$ & 123,2 & 0,139 & $-0,577$ \\
\hline
\end{tabular}


Table 4. Probability of existence of organic compounds with certain free energy (Helmholtz energy) of formation at $100 \mathrm{~K}$ in GMC

\begin{tabular}{|c|c|c|}
\hline № & Compound & Probability of existence \\
\hline 1 & $\mathrm{CO}$ & 0,00103 \\
\hline 2 & $\mathrm{CS}$ & 0,00158 \\
\hline 3 & $\cos$ & 0,00199 \\
\hline 4 & $\mathrm{C}_{2} \mathrm{O}$ & 0,00180 \\
\hline 5 & $\mathrm{CO}_{2}$ & 0,00204 \\
\hline 6 & $\mathrm{C}_{2} \mathrm{~S}$ & 0,00171 \\
\hline 7 & $\mathrm{C}_{2} \mathrm{H}_{2}$ & 0,00309 \\
\hline 8 & $\mathrm{H}_{2} \mathrm{CO}$ & 0,00295 \\
\hline 9 & $\mathrm{H}_{2} \mathrm{CS}$ & 0,00281 \\
\hline 10 & $\mathrm{HNCO}$ & 0,00261 \\
\hline 11 & $\mathrm{HOCN}$ & 0,00270 \\
\hline 12 & HSCN & 0,00223 \\
\hline 13 & $\mathrm{c}-\mathrm{SiC}_{3}$ & 0,00208 \\
\hline 14 & $\mathrm{CH}_{4}$ & 0,00380 \\
\hline 15 & $\mathrm{CH}_{2} \mathrm{CO}$ & 0,00323 \\
\hline 16 & $\mathrm{CH}_{2} \mathrm{NH}$ & 0,00357 \\
\hline 17 & $1-\mathrm{C}_{3} \mathrm{H}_{2}$ & 0,00323 \\
\hline 18 & c- $\mathrm{C}_{3} \mathrm{H}_{2}$ & 0,00312 \\
\hline 19 & $\mathrm{HCCCN}$ & 0,00308 \\
\hline 20 & $\mathrm{HC}_{2} \mathrm{NC}$ & 0,00275 \\
\hline 21 & $\mathrm{HC}(\mathrm{O}) \mathrm{CN}$ & 0,00294 \\
\hline 22 & $\mathrm{HCOOH}$ & 0,00327 \\
\hline 23 & $\mathrm{NH}_{2} \mathrm{CN}$ & 0,00336 \\
\hline 24 & $\mathrm{SiH}_{4}$ & 0,00302 \\
\hline 25 & $\mathrm{CH}_{3} \mathrm{OH}$ & 0,00387 \\
\hline 26 & $\mathrm{CH}_{3} \mathrm{CN}$ & 0,00375 \\
\hline 27 & $\mathrm{CH}_{3} \mathrm{NC}$ & 0,00372 \\
\hline 28 & $\mathrm{H}_{2} \mathrm{CCNH}$ & 0,00372 \\
\hline 29 & $\mathrm{NH}_{2} \mathrm{CHO}$ & 0,00369 \\
\hline 30 & HCCCHO & 0,00350 \\
\hline 31 & $\mathrm{c}-\mathrm{H}_{2} \mathrm{C}_{3} \mathrm{O}$ & 0,00357 \\
\hline 32 & $\mathrm{CH}_{3} \mathrm{SH}$ & 0,00370 \\
\hline 33 & $\mathrm{CH}_{2} \mathrm{CHCN}$ & 0,00386 \\
\hline 34 & $\mathrm{CH}_{3} \mathrm{NH}_{2}$ & 0,00384 \\
\hline 35 & $\mathrm{HC}_{5} \mathrm{~N}$ & 0,00359 \\
\hline 36 & $\mathrm{CH}_{3} \mathrm{CHO}$ & 0,00390 \\
\hline 37 & $\mathrm{H}_{2} \mathrm{CCHOH}$ & 0,00391 \\
\hline 38 & c- $\mathrm{C}_{2} \mathrm{H}_{4} \mathrm{O}$ & 0,00390 \\
\hline 39 & $\mathrm{CH}_{3} \mathrm{CCH}$ & 0,00390 \\
\hline 40 & $\mathrm{CH}_{3} \mathrm{CCCN}$ & 0,00390 \\
\hline 41 & $\mathrm{HCOOCH}_{3}$ & 0,00390 \\
\hline 42 & $\mathrm{CH}_{3} \mathrm{COOH}$ & 0,00387 \\
\hline 43 & $\mathrm{H}_{2} \mathrm{C}_{6}$ & 0,00381 \\
\hline 44 & $\mathrm{CH}_{2} \mathrm{OHCOH}$ & 0,00390 \\
\hline 45 & 1- $\mathrm{HC}_{6} \mathrm{H}$ & 0,00387 \\
\hline 46 & $\mathrm{CH}_{2} \mathrm{CHCHO}$ & 0,00389 \\
\hline 47 & $\mathrm{CH}_{2} \mathrm{CCHCN}$ & 0,00390 \\
\hline 48 & $\mathrm{H}_{2} \mathrm{NCH}_{2} \mathrm{CN}$ & 0,00386 \\
\hline 49 & $\mathrm{CH}_{3} \mathrm{CH}_{2} \mathrm{OH}$ & 0,00332 \\
\hline
\end{tabular}




\begin{tabular}{lcl}
\hline 50 & $\mathrm{CH}_{3} \mathrm{C}_{4} \mathrm{H}$ & 0,00375 \\
51 & $\mathrm{CH}_{3} \mathrm{CH}_{2} \mathrm{CN}$ & 0,00356 \\
52 & $\mathrm{HC}_{7} \mathrm{~N}$ & 0,00387 \\
53 & $\mathrm{CH}_{3} \mathrm{OCH} H_{3}$ & 0,00336 \\
54 & $\mathrm{CH}_{3} \mathrm{C}(\mathrm{O}) \mathrm{NH}_{2}$ & 0,00362 \\
55 & $\mathrm{C}_{3} \mathrm{H}_{6}$ & 0,00332 \\
56 & $\left(\mathrm{CH}_{3}\right)_{2} \mathrm{CO}$ & 0,00307 \\
57 & $\mathrm{CH}_{3} \mathrm{C}_{5} \mathrm{~N}$ & 0,00376 \\
58 & $\left(\mathrm{CH}_{2} \mathrm{OH}\right)_{2}$ & 0,00314 \\
59 & $\mathrm{CH}_{3} \mathrm{CH}_{2} \mathrm{CHO}$ & 0,00309 \\
60 & $\mathrm{NH}_{2} \mathrm{CH}_{2} \mathrm{COOH}$ & 0,00336 \\
61 & $\mathrm{CH}_{3} \mathrm{C}_{6} \mathrm{H}$ & 0,00335 \\
62 & $\mathrm{C}_{2} \mathrm{H}_{5} \mathrm{OCHO}$ & 0,00290 \\
63 & $\mathrm{HC}_{9} \mathrm{~N}$ & 0,00387 \\
64 & $\mathrm{C}_{2} \mathrm{H}_{5} \mathrm{OCH}$ & 0,00178 \\
65 & ${\mathrm{n}-\mathrm{C}_{3} \mathrm{H}_{7} \mathrm{CN}}_{66}$ & 0,00204 \\
67 & $\mathrm{C}_{6} \mathrm{H}_{6}$ & 0,00219 \\
\hline
\end{tabular}

Table 5. Gas resources in Space (calculated on free energy)

\begin{tabular}{cccc}
\hline \multirow{2}{*}{ Compound } & \multicolumn{3}{c}{ The amount of resources in Sun's mass at T, K } \\
\cline { 2 - 4 } & 100 & 300 & 500 \\
\hline Methane & $38 \cdot 10^{12}(38 \%)$ & $43 \cdot 10^{12}(43 \%)$ & $45 \cdot 10^{12}(45 \%)$ \\
Ethane & $35 \cdot 10^{12}(35 \%)$ & $40 \cdot 10^{12}(40 \%)$ & $37 \cdot 10^{12}(37 \%)$ \\
Propane & $19 \cdot 10^{12}(19 \%)$ & $21 \cdot 10^{12}(21 \%)$ & $19 \cdot 10^{12}(19 \%)$ \\
Butane & $7 \cdot 10^{12}(7 \%)$ & $6 \cdot 10^{12}(6 \%)$ & $6 \cdot 10^{12}(6 \%)$ \\
Pentane & $1 \cdot 10^{12}(1 \%)$ & $1 \cdot 10^{12}(1 \%)$ & $1 \cdot 10^{12}(1 \%)$ \\
\hline
\end{tabular}

Table 6. Oil hydrocarbons resources in Space (calculated on free energy)

\begin{tabular}{cccc}
\hline \multirow{2}{*}{ Compound } & \multicolumn{3}{c}{ The amount of resources in Sun's mass at T, K } \\
\cline { 2 - 4 } & 100 & 300 & 500 \\
\hline Benzene & $22 \cdot 10^{12}$ & $25 \cdot 10^{12}$ & $24 \cdot 10^{12}$ \\
Naphthalene & $3 \cdot 10^{12}$ & $3 \cdot 10^{12}$ & $3 \cdot 10^{12}$ \\
Antracene & $9 \cdot 10^{10}$ & $6 \cdot 10^{10}$ & $14 \cdot 10^{10}$ \\
Cyclohexane & $7 \cdot 10^{11}$ & $4 \cdot 10^{11}$ & $4 \cdot 10^{11}$ \\
Asphaltenes & $3 \cdot 10^{-10}$ & $6 \cdot 10^{-14}$ & $16 \cdot 10^{-10}$ \\
Hexane & $2 \cdot 10^{11}$ & $1 \cdot 10^{11}$ & $2 \cdot 10^{11}$ \\
Heptane & $13 \cdot 10^{9}$ & $6 \cdot 10^{9}$ & $16 \cdot 10^{9}$ \\
Octane & $6 \cdot 10^{8}$ & $2 \cdot 10^{8}$ & $8 \cdot 10^{8}$ \\
Nonyl hydride & $16 \cdot 10^{6}$ & $3 \cdot 10^{6}$ & $29 \cdot 10^{6}$ \\
Decane & $28 \cdot 10^{4}$ & $3 \cdot 10^{4}$ & $66 \cdot 10^{4}$ \\
$\mathrm{C}_{8} \mathrm{H}_{10}$ & $2 \cdot 10^{12}$ & $2 \cdot 10^{12}$ & $2 \cdot 10^{12}$ \\
$\mathrm{C}_{11} \mathrm{H}_{10}$ & $4 \cdot 10^{11}$ & $3 \cdot 10^{11}$ & $5 \cdot 10^{11}$ \\
$\mathrm{C}_{16} \mathrm{H}_{10}$ & $2 \cdot 10^{10}$ & $1 \cdot 10^{10}$ & $4 \cdot 10^{10}$ \\
$\mathrm{C}_{16} \mathrm{H}_{14}$ & $23 \cdot 10^{7}$ & $6 \cdot 10^{7}$ & $43 \cdot 10^{7}$ \\
\hline
\end{tabular}




\section{Conclusions}

It is obvious that data of our calculations can be confirmed surely only in the future with development of astronomical instruments of observation and cosmonautics. Nevertheless already now there are data and facts of the astrophysics, confirming ideas of presented article. In this regard the data obtained in 2011 by Sun Kwok, and Yong Zhang (astrophysics from university of Hong Kong) on interpretation of the unknown infrared radiation (Unidentified Infrared Emission) of the interstellar environment in a fog Orion (Sun, 2013; Sun \& Yong, 2011) are interesting. IR spectrums of the interstellar environment testify to existence of substances, which are the analogs of oil pitches and asphaltenes. The uncovered compounds are characterized by the disorder combination of the aromatic rings connected among themselves by aliphatic chains of a various structure. These molecules include the functional groups which are including carbonyl, oxy, oxo and carboxyl groups, cyano group, tiofenovy and sulphide sulphur. These data confirm conclusions drawn by us still in 2002-2005 (Dolomatov, 2004, 2005; Dolomatov \& Kostyleva, 2002). It is interesting to note that in 2010 in Space were found (Cami et al., 2010) predicted in these works fullerene. Certainly, final justice of this hypothesis can be checked as a result of development of space researches of other planets and carrying out superdeep drilling of the interior Earth.

\section{References}

Anders, E., Hayatsu, R., \& Studier, M. H. (1973). Organic compounds in meteorites. Science, 182, 781-790. http://dx.doi.org/10.1126/science.182.4114.781

Anonymous. (ND). The Cologne Database for Molecular Spectroscopy: Molecules in Space. Universität zu Köln. Retrieved from http://www.astro.uni-koeln.de/cdms/molecules

Bains I. (2006). Molecular line mapping of the giant molecular cloud associated with RCW $106-$ I. 13CO. Monthly Notices of the Royal Astronomical Society, 367(4), 1609. http://dx.doi.org/10.1111/j.1365-296 6.2006.10055.x

Binney, J, \& Merrifield, M. (1998). Galactic Astronom. USA, Princeton: Princeton University Press.

Cami, J., Bernard-Salas, J., Peeters, E., \& Elizabeth, M. S. (2010). Detection of C60 and C70 in a Young Planetary Nebula. Science, 329(5996), 1180-1182. http://dx.doi.org/10.1126/science.1192035

Dolomatov M. Y. (1990). Some physical and chemical forecasting aspects of multicomponent systems properties in the conditions of extreme influences. ZhVHO of D.I.Mendeleev, 35(5), 632-638.

Dolomatov M. Y. (2000). Chemical physics of multicomponent organic systems. - Ufa: IPNHP AN RB.

Dolomatov M. Y., \& Kostyleva, E. V. (2002). Features of abiogenous synthesis of organic substance in space natural systems and a problem of an oil origin. "Oil Processing and Petrochemistry": Materials of International scientific conference. - Ufa: State Unitary Enterprise Petrochemical Processing Institute.

Dolomatov M. Y., \& Zhuravleva, N. A. (2012a). Regularities of distribution of organic molecules in the interstellar environment and space oil origins. Development of a Sokolov-Eygenson hypothesis. "Oil and gas processing-2012": Materials of International scientific conference (pp. 9-15). - Ufa: State Unitary Enterprise Institute of Petrochemical Processing of the Bashkortostan Republic.

Dolomatov M. Y., \& Zhuravleva, N. A. (2012b). Regularities of the organic molecules in the interstellar environment distribution and a space origin of oil. Development of a Sokolov-Eygenson hypothesis. Materials of the 1st All-Russian conference on deep genesis of oil "Kudryavtsev's Readings". Moscow. Retrieved from http://conference.deepoil.ru/images/stories/docs/tema/28_Dolomatov-Zuravleva_Theses.pdf

Dolomatov M. Y., \& Zhuravleva, N. A. (2012c). Statistical models of distribution of organic substances structure in giant molecular clouds. High technologies, 6, 32-37.

Dolomatov M. Y., \& Zhuravleva, N. A. (2014).Certificate on the state registration (Russian Federation) of the computer program «Information system of an assessment of molecules resources of in the interstellar medium» № 2014611796. http://dx.doi.org/10.1007/s10509-014-1844-8

Dolomatov M. Y. (2005). Fragments of the real substance theory from the hydrocarbon systems to the galaxies. Chemistry. Moskow.

Dolomatov, M. Y. (2004). Features of equilibrium thermodynamics complex systems with chaos of chemical constitutions and allocation of organic matter in the space. Abstracts of International Conference on Complex Systems. USA, Florida, Texas.

Dolomatov, M. Y., \& Zhuravleva, N. A. (2012). The Thermodynamic models of Molecular chemical compound Distribution in the Giant Molecular Clouds Medium. Applied Physics Research, 4(4). 
Dolomatov, M. Y., \& Zhuravleva, N. A. (2013). Distribution of molecules in the interstellar media and cosmogenesis of oil and biosystems. Ufa: Publishing house of Institute of petroleum refining and petrochemistry. Retrieved from http:/www.inhp.ru/ru/info/2495.html

Dolomatov, M. Y., \& Zhuravleva, N. A. (2014). Astrophysics and Space Science, 351(1), 213-218. Retrieved from http://link.springer.com/article/10.1007/s10509-014-1844-8.

Eygenson, A. S. (1990). About quantitative research of formation of technogenic and natural hydrocarbonic systems by means of methods of mathematical modeling. Chemistry and technology of fuels and oils, 9, 3-8.

Eygenson, A. S. (1991). Experience of genetic interpretation of component and fractional structure and chemical characteristics sheeted and reservoir oil. Pre-print Vol. 15 INH FROM Academy of Sciences of the USSR. Tomsk.

Eygenson, A. S., \& Sheih-Ali, D. M. (1986). Regularities of the component and fractional structure and chemical characteristics of sheeted and reservoir oil. IHN pre-print SO AN USSR. Tomsk.

Grinberg, D. M. (1984). Interstellar dust: Structure and evolution. The Science World, 8, 66-77.

Horowitz, N. H. (1986). To utopia and back: the search for life in the solar system. New York: W. H. Freeman and Company.

Kolesnichenko, A. V., \& Marov, M. Y. (2006). Mechanics bases of heterogeneous environments in a circumsolar protoplanetary cloud: influence of firm particles on turbulence in a disk. Solar System Research, 40(1), 2-62. http://dx.doi.org/10.1134/S0038094606010011

Kudryavtsev, A. N. (1973). Oil and gas genesis.

Landau, L. D., \& Lifshitz, E. M. (1996). Statistical Physics (3rd Ed. Part), Oxford: Butterworth-Heinemann.

Lee, Y., Snell, R. L., \& Dickman, R. L. (1996). The cold, massive molecular cloud G216-2.5. 2: Structure and kinematics. Astrophysical Journal, 432(1), 167-180.

Lovas, F. J. (1986). Recommended Rest Frequencies for Observed Interstellar Molecular Microwave Transitions. J. Phys. Chem. Ref. Data, 15, 251-303. http://dx.doi.org/10.1063/1.555771

Lovas, F. J. (1992). Recommended Rest Frequencies for Observed Interstellar Molecular Microwave Transitions. J. Phys. Chem. Ref. Data, 21, 181-272. http://dx.doi.org/10.1063/1.555920

Lyubarsky, Y. E., \& Syunyaev, R. A. (1991). Astronomy and astrophysics. Physical Quantities: Dictionary M: Energoizdat, 1197-1229.

Makalkin A. B., \& Ziglina, I. N. (2012). Modeling formation of self-gravitating dust condensations and original planetesimals in a protoplanetary disk. The third Moscow Solar System Symposium, Moscow, Space Research Institute, 3MS3-PC-03.

Makalkin, A. B., Ziglina, I. N., Dorofeeva, V. A., \& Safronov, V. S. (1998). Structure of the protoplanetary disk embedded within the infalling envelope. In L. Celnikier, \& J. T. Thanh Van (Eds.), Planetary Systems: The Long View (pp. 73-76).

Maloney, P. (1986). In NASA. Ames Research Center Summer School on Interstellar Processes: Abstracts of Contributed Papers.

Marov, M. Y., \& Kolesnichenko, A. V. (2012). Turbulence and selforganizing: problems modelling of space and environments. Berlin: Springer.

Miller, S. L. (1953). A production of amino acids under possible primitive earth conditions. Science, 117(3046), 528-9. http://dx.doi.org/10.1126/science.117.3046.528

Pascale, E., \& Steven, B. C. (2000). Organic molecules in the interstellar medium, comets, and meteorites: a voyage from dark clouds to the early earth. Annu. Rev. Astron. Astrophys, 38, 427-83. http://dx.doi.org/10. 1146/annurev.astro.38.1.427

Rudnitsky, G. M. (ND). Lectures on radio astronomy. Chapter 5. The interstellar environment and star formation areas in the Galaxy.

Sakamoto, S. (1999). Physical Conditions of Molecular Gas in the Galaxy. Astrophys. J., 523, 701. http://dx.doi.org/10.1086/307741

Sun, K. (2013). Stardust. The Cosmic Seeds of Life. Springer-Verlag Berlin Heidelberg. 
Sun, K., \& Yong, Z. (2011). Mixed aromatic-aliphatic organic nanoparticles as carriers of unidentified infrared emission features. Nature, 479, 80-83. http://dx.doi.org/10.1038/nature10542

Thomas Gold. (1988). The Deep Hot Biosphere. Copernicus, An Imprint of Springer-Verlag, New York.

Tsvetkov, A. G., \& Shematovich, V. I. (2009). The kinetic Monte-Carlo method for modeling of astrochemical kinetics: trial calculations of formation of molecular hydrogen on interstellar dust particles. AVATARS, 43(4), 315-327.

Tsvetkov, A. G., \& Shematovich, V. I. (2010). The kinetic Monte-Carlo method for modeling of astrochemical kinetics: hydrogen chemistry in diffusion clouds. AVATARS, 44(3), 195-208.

Vasyunin A. (2008). Development of the theory of numerical simulation of the molecular composition of the interstellar medium. PhD thesis, Physical institute of P. N. Lebedev of the Russian Academy of Sciences, Moscow.

Voytkevich, G. V. (1988). Origin and development of life on Earth. Planet Earth and Universe" series. M Science, 144.

Wickramasinghe, C. (2003). Panspermia according to Hoyle. Astrophysics and Space Science, 285(2), 535-538. http://dx.doi.org/10.1023/A:1025437920710

Yamada, K. M., \& Winnewisser, G. (Eds.). (2011). Interstellar Molecules: Their Laboratory and Interstellar Habitat (Vol. 241). Springer. http://dx.doi.org/10.1007/978-3-642-16268-8

\section{Copyrights}

Copyright for this article is retained by the author(s), with first publication rights granted to the journal.

This is an open-access article distributed under the terms and conditions of the Creative Commons Attribution license (http://creativecommons.org/licenses/by/3.0/). 